\title{
Espécies nativas do Bioma Pampa para uso como folhagem de corte ${ }^{(1)}$
}

\author{
ELISABETH R. TEMPEL STUMPF(2); GUSTAVO HEIDEN(3); ROSA LIA BARBIERI(4); \\ SÍNTIA Z. FISCHER ${ }^{(2)}$ e RAQUEL S. NEITZKE ${ }^{(2)}$
}

\begin{abstract}
RESUMO
O lançamento de novas plantas no mercado tem início na definição das características que as qualificam como ornamentais. A identificação dessas plantas dentre a vegetação natural, aliada à produção em escala comercial, valoriza e colabora para a preservação da flora de uma região, podendo, ainda, promover o desenvolvimento e imprimir competitividade à Floricultura local. A composição vegetal do Rio Grande do Sul, certamente, abriga espécies com características ornamentais adequadas para uso em arranjos florais. Nativas da região sul do Estado, as espécies Baccharis articulata, B. usterii, Hypericum connatum, Myrsine umbellata, Schinus lentiscifolius e S. terebinthifolius mostram características desejáveis para uso como folhagens de corte. Assim, este trabalho foi desenvolvido com o objetivo de descrever as características ornamentais dessas espécies, averiguando seu potencial para uso como folhagens de corte. A caracterização ornamental teve como base a avaliação de atributos qualitativos e quantitativos, que receberam as notas zero, cinco ou dez. As espécies avaliadas apresentam alto grau de potencialidade ornamental, mostrando características adequadas para o uso como complementos de arranjos florais.
\end{abstract}

Palavras-chave: Baccharis, Hypericum, Myrsine, Schinus, atributos estéticos, floricultura

\author{
ABSTRACT \\ Native species from the Pampa Biome, Southern Brazil, for use as florist green
}

\begin{abstract}
The introduction of news plants in the market begins with the definition of characteristics that qualify them as ornamental. Identification of these plants in the natural vegetation, and his production in commercial scale, gives value and collaborates for the preservation of the regional flora, being able to promote the development and competitiveness for local Floriculture. The vegetal composition of Rio Grande do Sul State is formed by species with desirable characteristics for use in floral arrangements. This work was developed to describe the ornamental characteristics of Baccharis articulata, B. usterii, Hypericum connatum, Myrsine umbellata, Schinus lentiscifolius and S. terebinthifolius, native species from Southern of the State, for use as cut foliages. The ornamental characterization was based in the evaluation of quantitative and qualitative attributes, which received scores zero, five or ten. The study showed that these species present high ornamental potential, showing adequate characteristics for use as floral arrangements complements.
\end{abstract}

Keywords: Baccharis, Hypericum, Myrsine, Schinus, aesthetic attributes, floriculture.

\section{INTRODUÇÃO}

A inclusão de plantas nativas na cadeia produtiva da Floricultura oferece uma estratégia de mercado considerável, tanto para produtores tradicionais como para os que começam a investir na atividade. Seus clientes, sejam atacadistas, varejistas ou consumidores finais, almejam por produtos que apresentem novas tendências, haja vista a utilização de flores e folhagens de corte, basicamente, para fins decorativos. Tendências, em arranjos florais, envolvem a originalidade de cores, formatos e texturas, e/ou usos inovadores, o que se traduz no uso de plantas com características ornamentais diferenciadas. O ponto de partida para o lançamento de novas plantas no mercado é a definição das características que as qualificam como ornamentais. A identificação dessas plantas dentre a vegetação natural de determinada região, associada à posterior produção em escala comercial, não apenas valoriza e colabora para a preservação da flora, como também, transforma-se em oportunidade para promover o desenvolvimento e imprimir competitividade aos floricultores.

O Bioma Pampa se restringe ao Rio Grande do Sul e ocupa $63 \%$ do território do Estado (IBGE 2007), apresentando vegetação composta por campos, florestas e restingas (LEITE, 2002; QUADROS e PILLAR, 2002; MARCHIORI, 2002). Os campos apresentam uma diversidade de plantas expressiva, com destaque das

\footnotetext{
(1) Recebido para publicação em 21/6/2007 e aceito em 21/8/2008.

(2) Universidade Federal de Pelotas, Pelotas (RS). e-mail: elisabeth.stumpf@gmail.com

(3) Jardim Botânico do Rio de Janeiro (RJ). Colocar o endereço

${ }^{(4)}$ Embrapa Clima Temperado, Pelotas (RS). Colocar o endereço
} 
representantes das famílias Poaceae, Asteraceae, Leguminosae e Cyperaceae (BOLDRINI, 2006). A floresta estacional semidecidual não apresenta espécies exclusivas (GLUFKE, 1999) e age como área de transição entre a região costeira e a estacional do interior, com importante influência do oceano sobre a seleção florística. As restingas, por sua vez, estendem-se ao longo dos $600 \mathrm{~km}$ da costa litorânea, com vegetação principalmente herbácea, em que ressaltam as gramíneas e espécies subarbustivas (QUADROS e PILLAR, 2002).

Considerando essa diversidade fitofisionômica e florística, é de supor que existam inúmeras espécies com potencial para uso como folhagens de corte, também denominadas verdes de corte, ou apenas verdes. As folhagens de corte são obtidas pelo cultivo de espécies herbáceas, arbustivas ou arbóreas, para o aproveitamento de suas folhas ou ramos na confecção de arranjos florais. As folhagens são empregadas como complemento ou fundo para destacar ou criar contraste entre os elementos, dar sustentação aos arranjos, preencher espaços vazios ou forrar as bases onde o arranjo é montado. São usadas também para conferir textura ou interesse visual e atuar sobre o volume ou a altura do conjunto (BASKETT e SMITH, 2006). Versáteis, as folhagens diferenciam composições florais. Por exemplo, um arranjo composto por rosas e samambaia-preta assume visual bastante distinto quando esta é substituída pelo junco ou por folhas de camélias.

$\mathrm{Na}$ região sul do Rio Grande do Sul foram identificadas algumas espécies nativas que, pelo aspecto dos ramos e folhas, apresentam qualidades estéticas que indicam possibilidade de uso como folhagens de corte. São elas Baccharis articulata (Lam.) Pers. (carquejinha), B. usterii Heering (carqueja-do-banhado), Hypericum connatum Lam. (orelha-de-gato), Myrsine umbellata Mart. (capororoca), Schinus lentiscifolius Marchand (aroeiracinzenta) e $S$. terebinthifolius Raddi (aroeira-vermelha) (figura 1). Assim, o presente trabalho foi desenvolvido com o objetivo de descrever as características ornamentais dessas seis espécies, verificando seu potencial para uso como folhagens de corte.

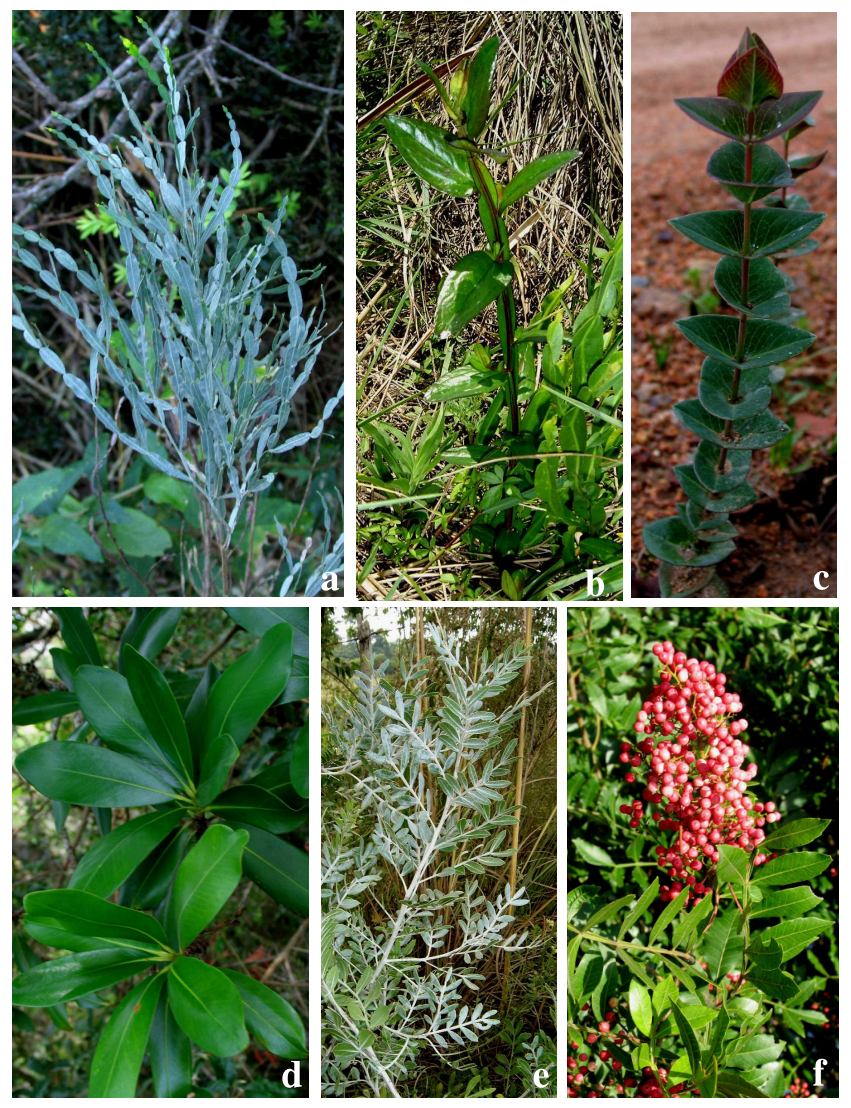

Figura 1. Baccharis articulata (a), B. usterii (b), Hypericum connatum (c), Myrsine umbellata (d), Schinus lentiscifolius (e), S. terebinthifolius (f).

Figure 1. Baccharis articulata (a), B. usterii (b), Hypericum connatum (c), Myrsine umbellata (d), Schinus lentiscifolius (e), S. terebinthifolius $(f)$. 


\section{MATERIAL E MÉTODOS}

Os locais de ocorrência de Baccharis articulata, B. usterii, Hypericum connatum, Myrsine umbellata, Schinus lentiscifolius e S. terebinthifolius foram determinados pelas indicações de agricultores, estudantes, pesquisadores e moradores da zona rural e, também, por consulta a bibliografia especializada e a acervos de herbários. Para tanto, foram consultados os herbários da Embrapa Clima Temperado (HECT), Universidade de Caxias do Sul (HUCS), Fundação Universidade Federal do Rio Grande (HURG), Universidade Federal do Rio Grande do Sul (ICN), Universidade Federal de Pelotas (PEL) e Instituto Anchietano de Pesquisas (PACA).

De posse desses dados, foram escolhidas populações naturais e acompanhado o desenvolvimento das plantas, a fim de verificar a época em que apresentavam os atributos estéticos desejados para efetuar a coleta dos ramos e/ou folhas e realizar a caracterização ornamental. Realizaram-se as coletas nos anos de 2005 e 2006, em zonas rurais dos municípios de Canguçu e Pelotas, RS. Para a caracterização ornamental, foram utilizados os critérios propostos por STUMPF (2007), por meio da análise de características qualitativas e quantitativas de importância para a arte floral e para o mercado consumidor (tabela 1). Cada espécie foi caracterizada isoladamente, na fase em que apresentavam o ponto de maior interesse ornamental. Para cada uma das características foram conferidas as notas 0 (zero), 5 (cinco) ou 10 (dez). Coletaram-se ramos de Baccharis usterii, Hypericum connatum, Myrsine umbellata e Schinus lentiscifolius na fase vegetativa, ramos de $B$. articulata no início da fase reprodutiva e ramos de $S$. terebinthifolius com frutos.

Para a avaliação da vida útil real (STUMPF, 2007), utilizaram-se 40 ramos de Baccharis articulata, B. usterii, Hypericum connatum, Schinus lentiscifolius e $S$. terebinthifolius e 40 folhas de Myrsine umbellata. $\mathrm{O}$ comprimento dos ramos de B. articulata, B. usterii, Schinus lentiscifolius e $S$. terebinthifolius foi uniformizado em $40 \mathrm{~cm}$ e os de Hypericum connatum em $50 \mathrm{~cm}$, sendo retiradas todas as folhas do terço basal. As folhas de M. umbellata foram selecionadas pelo tamanho médio e integridade do limbo e tiveram o comprimento do pecíolo uniformizado em $4 \mathrm{~cm}$. Após esse procedimento, os ramos e folhas de cada espécie foram acondicionados em recipientes preenchidos com água de saneamento urbano e, em outros, com espuma floral saturada. Efetuou-se a avaliação em laboratório, por um período mínimo 30 dias, sendo mantidos pela adição periódica de água o nível da água e a saturação da espuma floral.

Ainda com base na metodologia de STUMPF (2007), avaliou-se o grau de potencialidade ornamental das seis espécies, como resultado da soma das notas concedidas às características avaliadas:

- Acima de 70 pontos - alta potencialidade ornamental;

- Acima de 50 até 70 pontos - média potencialidade ornamental;

- Acima de 25 até 50 pontos - baixa potencialidade ornamental;

- 25 pontos ou menos -mínima potencialidade ornamental.

\section{RESULTADOS E DISCUSSÃO}

Os resultados das avaliações estão apresentados na tabela 2 e são discutidos de forma individual no texto.

\subsection{Baccharis articulata}

Conhecida como carqueja, carqueja-branca ou carquejinha (figura 2), é um arbusto com altura média de $1,5 \mathrm{~m}$, ereto, muito ramificado e com caule trialado nas plantas jovens e bialado nas adultas (HEIDEN, 2005). O rendimento na composição floral, neste caso resultante do número de ramificações, é um aspecto positivo para a arte floral, pois contribui para o aumento do volume das composições florais e também para o rendimento, entendido como o número de estruturas de uma haste ou ramo, que pode ser utilizado pelo artista floral . Na fase em que foram coletados, no início da formação dos botões florais, não se percebeu o aroma agradável que as flores em estágio mais avançado exalam. A coloração dos ramos foi classificada como verde-acinzentada (CMYK 50-40100-0 e 60-40-100-0). A cor, bastante diversa das apresentadas pelos complementos florais tradicionais, pode conferir um diferencial para os arranjos. $\mathrm{O}$ aspecto geral da haste foi considerado elemento com boa interferência visual, podendo acrescentar valor estético expressivo às composições florais. A forma dos ramos evidencia a originalidade da espécie quando comparada com outras folhagens de corte disponíveis no mercado do Sul do Rio Grande do Sul. O comprimento dos ramos coletados mostrou valores superiores a $50 \mathrm{~cm}$ e rigidez adequada, o que possibilita o uso em diferentes estilos de composições florais. Em água, a vida útil real média foi de 19 dias e, em espuma floral, de 16 dias. Com base nas notas atribuídas (tabela 2), a espécie demonstra alta potencialidade ornamental para o uso pretendido.

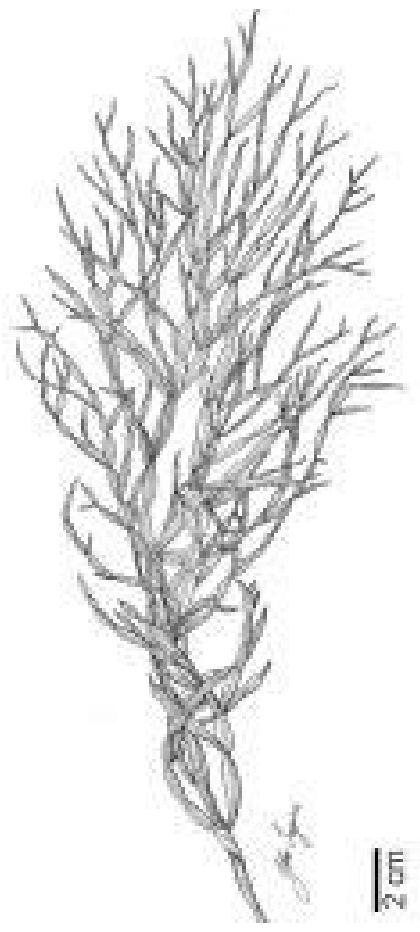

Figura 2. Baccharis articulata.

Figure 2. Baccharis articulata. 


\subsection{Baccharis usterii}

HEIDEN (2005) descreve a carqueja-do-banhado (Figura 3) como um subarbusto ramificado, com estatura entre 0,5 e $1,5 \mathrm{~m}$. O caule é trialado, com alas planas ou levemente onduladas, e as folhas são curtamente pecioladas, com limbo oblongo a ovalado. A uniformidade e comprimento dos ramos permitem amplitude de usos e mostra, também, a originalidade da espécie frente às folhagens que o mercado do Sul do Rio Grande do Sul oferece. A verticalidade e a uniformidade da largura (média de $3 \mathrm{~cm}$ ) dos ramos evidenciam o inusitado da forma, mas contribuem medianamente para o rendimento das composições florais. Em grupo, a rigidez e o formato dos ramos dessa carqueja podem ser aproveitados para a formação de tuchos (agrupamento denso de ramos empregado para a sustentação de flores e folhagens em arranjos), a exemplo do que é feito com hastes de junco (Juncus spp.) ou de cavalinha (Equisetum arvense) (JANNINI, 1998).

O comprimento médio $(108 \mathrm{~cm})$ apresentado pelos ramos coletados na população escolhida possibilita o uso em combinação com a maior parte das flores de corte tradicionalmente utilizadas em arranjos, como cravos, gérberas e rosas, cujo padrão máximo é de 90,40 e $70 \mathrm{~cm}$ respectivamente (IBRAFLOR, 2000). Os ramos foram coletados na fase vegetativa, quando apresentavam uma média de 24 folhas, com tamanho médio de 3,2 $\mathrm{cm} \mathrm{x} \mathrm{1,5}$ $\mathrm{cm}$ e sem aroma perceptível. A carqueja-do-banhado apresenta ramos e folhas brilhosas. A coloração dos ramos foi determinada como verde-médio (CMYK 60-40-1000 ) e a das folhas, ligeiramente mais clara, classificada como verde (CMYK 60-30-100-0). O maior valor ornamental dessa espécie encontra-se na forma e no aspecto geral, do que na cor, que foi considerada comum quando comparada à cor de outras folhagens de corte. A vida útil real média foi de 16 dias para os ramos acondicionados em recipientes com água e de apenas quatro dias para aqueles mantidos em espuma floral. Portanto, o uso dessa espécie em espuma floral, deve limitar-se a decorações de eventos de curta duração. Pelas notas atribuídas a cada uma das características avaliadas (tabela 2), o grau de potencialidade ornamental dessa espécie para uso na arte floral foi considerado alto.

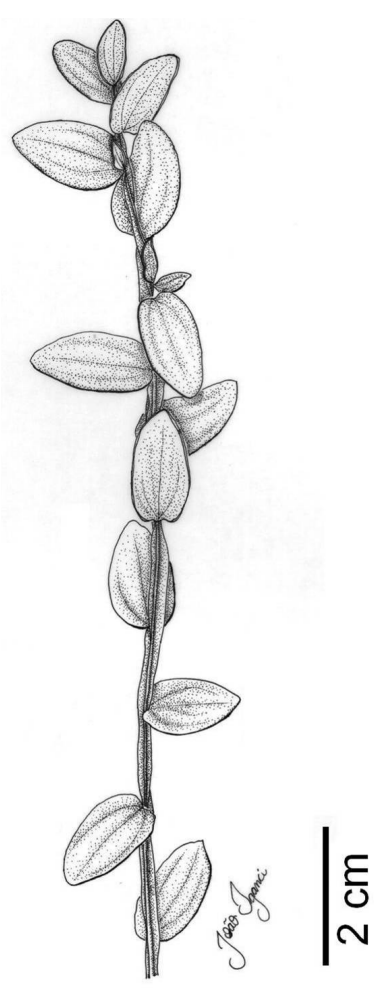

Figura 3. Baccharis usterii. Figure 3. Baccharis usterii.

\subsection{Hypericum connatum}

A orelha-de-gato ou espetinho (figura 4) atinge uma altura média de $60 \mathrm{~cm}$ (JIMÉNEZ, 1980), o que possibilita um bom uso na arte floral. Possui caule simples, com diâmetro médio de $0,15 \mathrm{~cm}$, adequada rigidez e coloração avermelhada (CMYK 40-70-100-0). Os caules possuem cerca de 20 folhas opostas, de coloração verde-acinzentada (CMYK 50-40-90-0), com nervuras amareladas e bordos avermelhados (CMYK 20-100-90-0). O tamanho médio das folhas foi calculado em $3,2 \mathrm{~cm}$ x 1,9 cm. A coloração e a forma inusitada dos caules dessa espécie são aspectos capazes de interferir positivamente em composições florais. Embora se assemelhem vagamente ao Eucaflor (Eucalyptus cinerea), árvore cujos ramos são bastante utilizados em arranjos e decorações, é possível afirmar que os caules do espetinho são produtos bastante originais para uma futura inserção no mercado. Por possuir haste única, a espécie contribui medianamente para o volume de composições 
florais. Igualmente sem destaque é a característica aroma, pois no ponto coletado a espécie não exalou notadamente nenhum odor. A vida útil real média em água foi de 19 dias e em espuma floral, de 17 dias. Pelo escore obtido (Tabela 2), H. connatum foi considerada uma espécie com alto potencial ornamental.

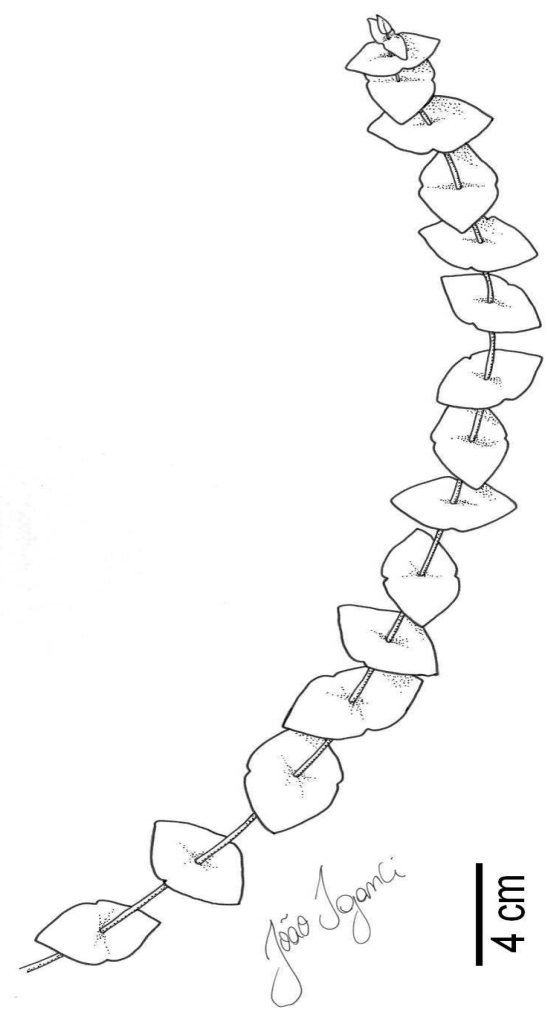

Figura 4. Hypericum connatum. Figure 4. Hypericum connatum

\subsection{Myrsine umbellata}

A capororoca (figura 5) é uma árvore da família Myrsinaceae que atinge $15 \mathrm{~m}$ de altura, cujas folhas grandes e coriáceas (VEITENHEIMER-MENDES et al., 2005) concentram-se nas pontas dos ramos. Para a caracterização ornamental foram utilizadas as folhas devido a sua beleza e brilho. Durante a caracterização não se detectou aroma expressivo nas folhas. O comprimento médio das folhas foi de $22 \mathrm{~cm}$ e a largura média de $9 \mathrm{~cm}$, medidas que possibilitam variadas opções de uso. As folhas podem, por exemplo, ser enroladas dentro de recipientes para servir como base de sustentação para os demais elementos de um arranjo floral, técnica denominada por JANNINI (1998) de rocambole de folhas. Por serem coriáceas, permitem o corte em diversos formatos, não necessitando de artifícios para que se mantenham eretas. A cor das folhas foi identificada como verde-escuro (CMYK 60-50-100-0), com nervura central verde-amarelado (CMYK 30-20-100-0). Embora não seja de todo incomum, o destaque da coloração se dá pelo brilho. O uso de folhas na arte floral não é inédito, já que floristas utilizam outras folhas em suas composições, como as de antúrio ou de estrelitízia. No entanto, a forma das folhas, obovada a elíptica, é bastante original quando se considera o mercado local. Quanto à característica aspecto da haste, neste caso específico foi considerado o aspecto do pecíolo, que não provoca qualquer interferência sobre a composição floral. Quando apreciado o rendimento em composições florais, é possível dizer que as folhas pouco contribuem para este quesito. Entretanto, considerando que a espécie tem, em média, 10 folhas por ramo, se comercializados e utilizados em ramos, o rendimento pode ser considerado alto. Ao final do período de 30 dias, todas as folhas mantidas em água estavam ainda em perfeitas condições de uso, sem alteração de cor ou forma. Em espuma floral, as folhas permaneceram com aspectos adequados por 28 dias, em média. A pontuação final mostrou alta potencialidade de uso da espécie como folhagem de corte (tabela 2). 


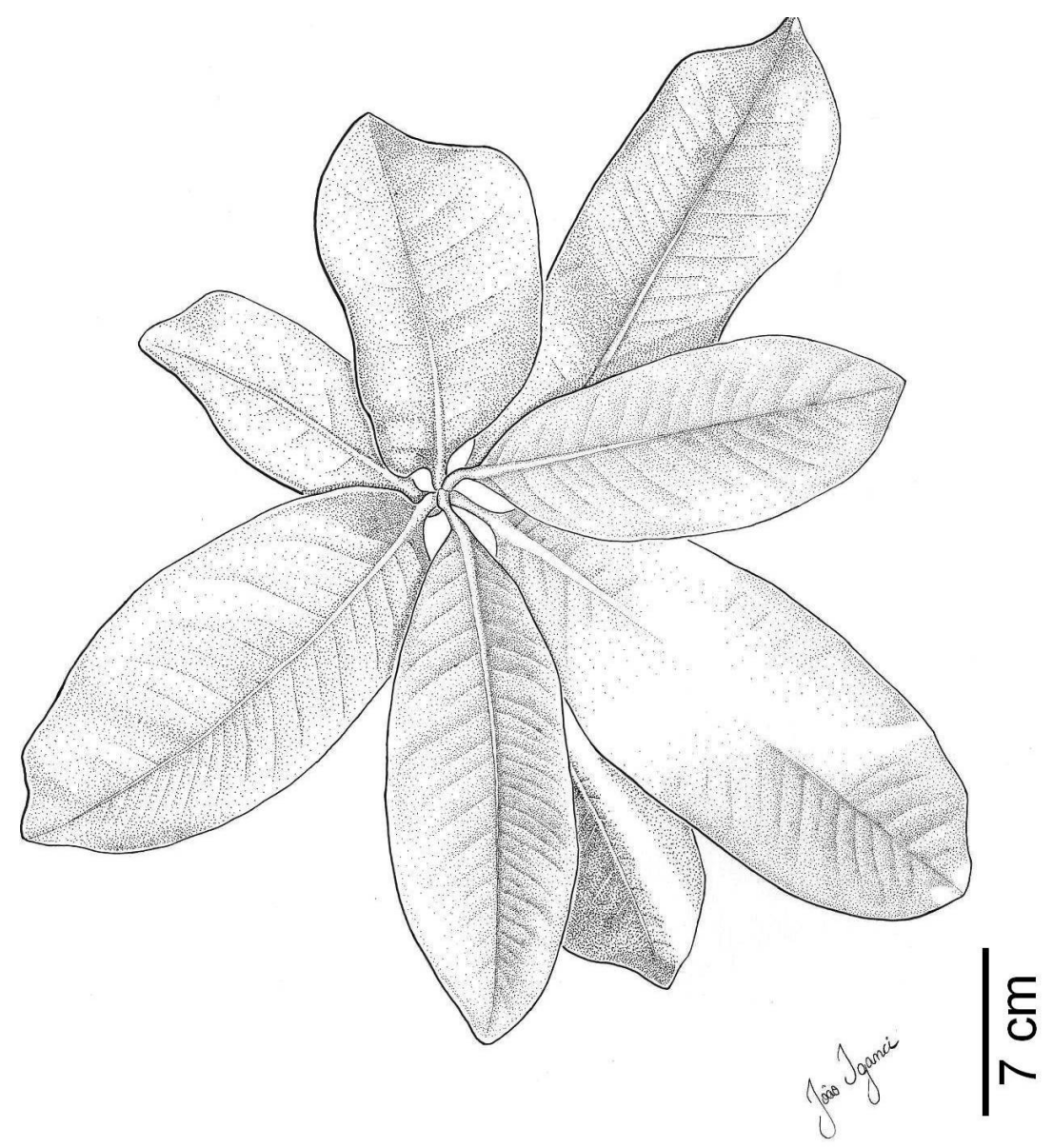

Figura 5. Myrsine umbellata.

Figure 5. Myrsine umbellata.

\subsection{Schinus lentiscifolius}

Schinus lentiscifolius (figura 6) é um arbusto que pode atingir até $3 \mathrm{~m}$ de altura e possui ramos com folhas compostas, imparipenadas, com folíolos oblongos. Pertencente à família Anacardiaceae, é conhecido popularmente como aroeira-cinzenta, aroeira-do-riogrande, carobá ou aroeira-do-campo (FLEIG, 1989). Na população estudada, os folíolos apresentaram cor verdeacinzentado na porção adaxial (CMYK 40-20-40-0) e cinza na porção abaxial, colaborando para a estética dos arranjos florais. Os ramos são aveludados e apresentaram igualmente a coloração acinzentada, aspecto bastante incomum para folhagens de corte, contribuindo positivamente para a estética das composições florais. Segundo ITTEN (1997), o cinza é uma cor neutra, que atenua a força das cores vizinhas e transmite harmonia e equilíbrio. Para a arte floral, a neutralidade do cinza é uma vantagem, já que não limita combinações com elementos de outras cores. Os ramos apresentaram valor médio de 27 folhas compostas, o que pode colaborar significativamente para agregar volume às composições florais. O comprimento médio dos ramos coletados foi superior a $40 \mathrm{~cm}$ e estes se mostraram firmes, dispensando o uso de tutoramento ou reforço artificial. A forma dos ramos e das folhas diferencia-se das folhagens de corte comercializadas, evidenciando uma desejada originalidade. $\mathrm{O}$ aroma observado mostrou-se bastante agradável e, segundo STUMPF et al. (2006), a espécie apresenta um teor expressivo de óleos essenciais $(1,2 \%)$ quando comparado ao de outras espécies aromáticas, como o alecrim $(0,6 \%)$, por exemplo. Em água, a vida útil real média foi de 27 dias e em espuma floral de 26 dias. A vida útil real média apresentada é mais um ponto a favor da indicação do uso de ramos de $S$. lentiscifolius como folhagem de corte. A espécie obteve a nota 10 para todas as características avaliadas, alcançando, segundo a metodologia empregada, o grau máximo de potencialidade ornamental (tabela 2). 


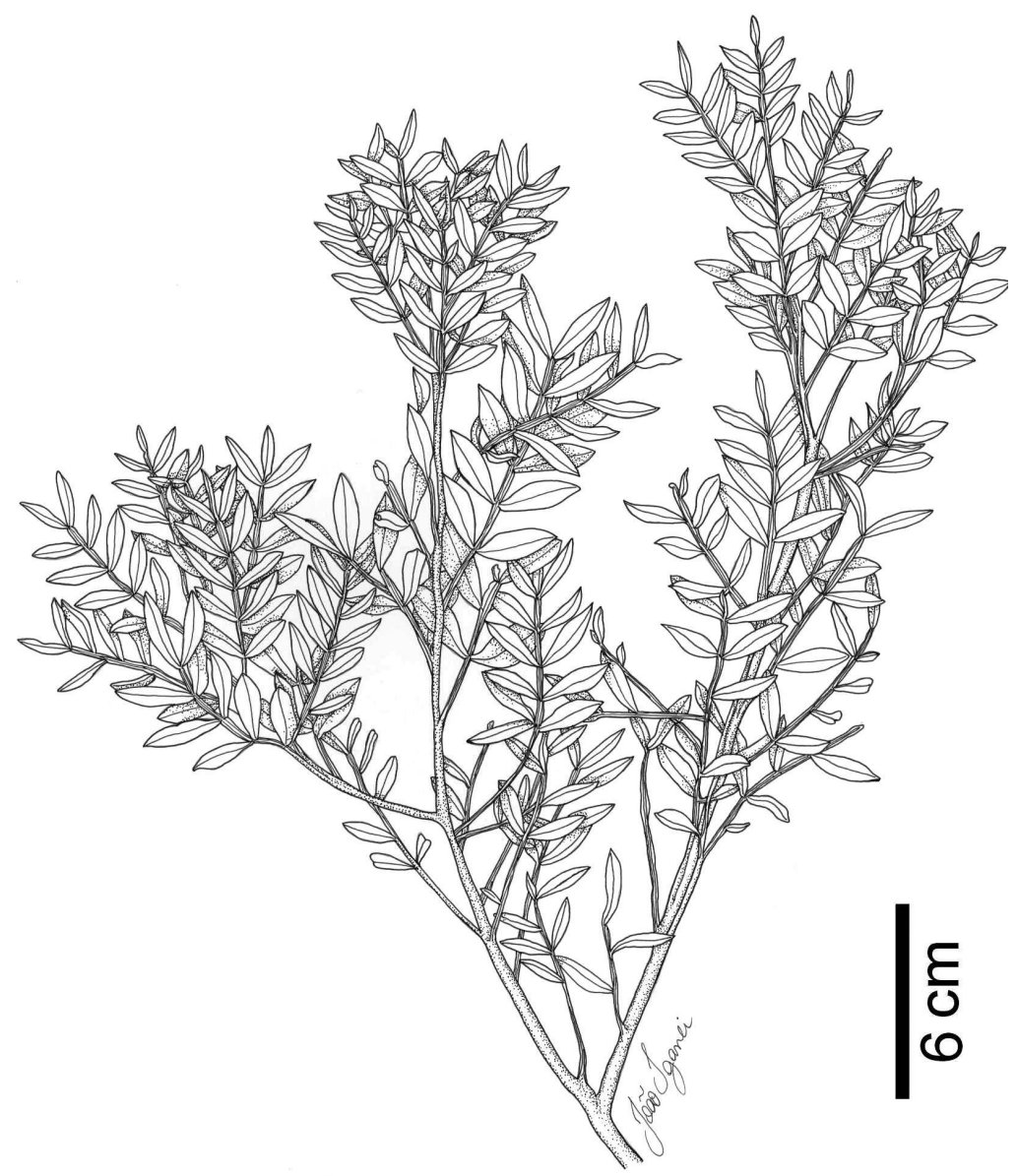

Figura 6. Schinus lentiscifolius. Figure 6. Schinus lentiscifolius

\subsection{Schinus terebinthifolius}

Schinus terebinthifolius (figura 7) pode atingir até $15 \mathrm{~m}$ de altura e é conhecida como aroeira-vermelha ou aroeira-mansa (FLEIG, 1989). A espécie é reconhecida como ornamental, mas apenas com utilização no paisagismo, em arborização de ruas e praças (SOUZA e LORENZI, 2005). Neste trabalho, a caracterização ornamental foi direcionada para o uso dos ramos com frutos na arte floral. Com aroma bastante agradável, os ramos apresentaram comprimento médio superior a $40 \mathrm{~cm}$, média de 11 folhas por ramo e cachos de frutos com comprimento médio de $17 \mathrm{~cm}$, o que pode contribuir marcantemente para o aumento do volume das composições. A cor de $50 \%$ das folhas foi determinada como verde-médio (CMYK 5030-90-0) e no restante como verde-escuro (CMYK 60-5090-0). Em algumas plantas os frutos encontravam-se mais concentrados no ápice dos ramos, enquanto em outras, mostraram-se distribuídos ao longo dos ramos. Os cachos apresentavam frutos brilhantes, em diferentes etapas de maturação, com cor variada desde o verde (CMYK 40-
30-90-0) e o rosa (CMYK 10-60-60-0) até o vermelhoescuro (CMYK 50-100-100-0). PEDROSA (1982) cita, dentre as cores, o vermelho como de maior destaque visual e, em conjunto com o verde, o que produz uma combinação vibrante. Para a arte floral, portanto, os aspectos que podem agregar valor são a forma singular dos cachos e a cor dos frutos. Os ramos mostraram adequada firmeza para uso na arte floral, mas o aspecto geral da haste não interfere na estética da composição floral. Na região em estudo não há espécie semelhante sendo cultivada e/ou utilizada pelos floristas, o que mostra sua originalidade como complemento floral. A vida útil real média dos ramos mantidos em água foi superior a 15 dias, mostrando adequação para a finalidade. Em espuma floral, no entanto, o aspecto estético se manteve apropriado por 12 dias em média, o que indica certa limitação para o uso nesse material (WEISS, 2002). Pela pontuação obtida em cada uma das características avaliadas, ramos de $S$. terebinthifolius com frutos apresentam alto grau de potencialidade ornamental para a arte floral (tabela 2). 


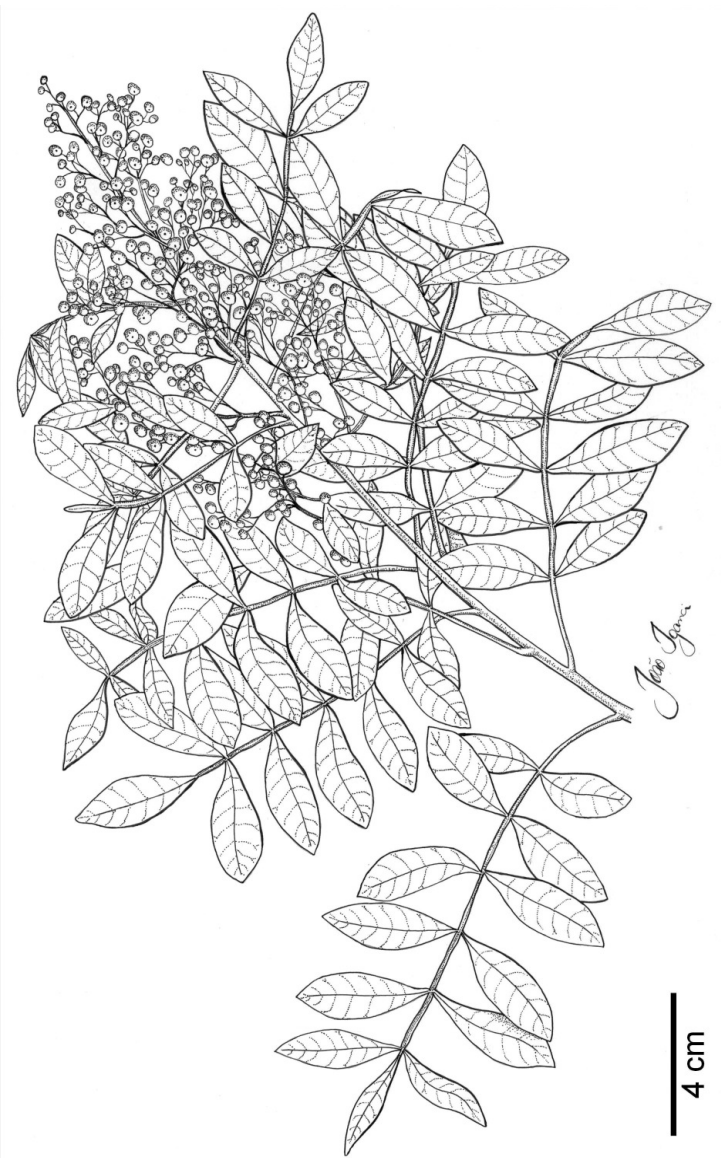

Figura 7. Schinus terebinthifolius.

Figure 7. Schinus terebinthifolius.

\section{CONCLUSÕES}

As espécies Baccharis articulata, B. usterii, Hypericum connatum, Myrsine umbellata, Schinus lentiscifolius e $S$. terebinthifolius, nativas do Bioma Pampa, no Sul do Rio Grande do Sul, mostram características adequadas para uso como folhagens de corte em arranjos florais.

\section{REFERÊNCIAS}

BASKETT, M.; SMITH, E. Classic floral designs. New York: Sterling Publishing Co Inc., 2006. 128p.

BOLDRINI, I.I. Diversidade florística nos campos do Rio Grande do Sul. Os avanços da botânica no início do século XXI. In: MARIATH, J.E.A.; SANTOS, R.P. (org). Os avanços da Botânica no início do século XXI: morfologia, fisiologia, taxonomia, ecologia e genética. 1.ed. Porto Alegre: Sociedade Botânica do Brasil, 2006, v. 1, p. 321-324.

FLEIG, M. Anacardiáceas. In: R. REITZ (ed.). Flora Ilustrada Catarinense, Itajaí: Herbário Barbosa Rodrigues, 1989, 62p.

GLUFKE, C. Espécies recomendadas para recuperação de áreas degradadas. Porto Alegre: Fundação Zoobotânica do Rio Grande do Sul, 1999. 48p.
HEIDEN, G. O gênero Baccharis L. secção Caulopterae DC. (Asteraceae) no Rio Grande do Sul. Pelotas: Universidade Federal de Pelotas, 2005. 238p. Monografia (Bacharelado em Ciências Biológicas).

IBGE. Mapas de Biomas e de vegetação. Disponível em: <http://www.ibge.gov.br/home/presidencia/noticias/ noticia_visualiza.php?id_noticia $=169>$. Acesso em 17/01/ 2008

IBRAFLOR. Padrão Ibraflor de qualidade. Campinas: Estúdio 66 Publicidade \& Marketing, 2000. 87p.

ITTEN, J. The art of color: the subjective experience and objective rationale of color. New York: Wiley Publishing, 1997. 160p.

JANNINI, K. Arranjos Florais. São Paulo: Ed. Europa Ltda., 1998, 82p.

JIMÉNEZ, C.R. Hipericáceas. In: R. REITZ (ed.). Flora Ilustrada Catarinense, Itajaí: Herbário Barbosa Rodrigues, 1980, 34p.

LEITE, P.F. Contribuição ao conhecimento fitoecológico do sul do Brasil. Ciência \& Ambiente, Santa Maria, v.24, p.52-73, jan./jun, 2002. 
MARCHIORI, J.N.C. Fitogeografia do Rio Grande do Sul - Enfoque histórico e sistemas de classificação. Porto Alegre: EST Edições, 2002. 118p.

PEDROSA, I. Da cor à cor inexistente. Rio de Janeiro: Léo Christiano Editorial Ltda, 1982. 224p.

QUADROS, F.L.F.; PILLAR, V.P. Transições florestacampo no Rio Grande do Sul. Ciência \& Ambiente, Santa Maria, v.24, p.109-118, 2002.

SOUZA, V.C.; LORENZI, H. Botânica Sistemática: guia ilustrado para identificação das famílias de Angiospermas da flora brasileira, baseado em APG II. Nova Odessa: Instituto Plantarum, 2005. 640p.

STUMPF, E.R.T.; SANTOS, A.C.A. dos; FISCHER, S.Z.; BARBIERI, R.L. HEIDEN, G.; ROSSATO, M. Óleos
Essenciais em Schinus lentiscifolius Marchand (Anacardiaceae). In: CONGRESSO BRASILEIRO DE BOTÂNICA, 57, Gramado, 2006. Anais... Porto Alegre, Sociedade Botânica do Brasil, 2006. CD-Rom.

STUMPF, E.R.T. Floricultura regional e potencialidade ornamental de plantas nativas do sul do Rio Grande do Sul. Pelotas: Universidade Federal de Pelotas, 2007. 157p. Tese (Doutorado em Agronomia).

VEITENHEIMER-MENDES, I.L.; MONDIN, C.A.; STREHL, T. (org). Guia ilustrado de fauna e flora para o Parque Copesul. Porto Alegre: Copesul, 2005. 207p.

WEISS, D. Introduction of new cut flowers: domestication of new species and introduction of new traits not found in commercial varieties. In: VAINSTEIN, A. Breeding for ornamentals. Dordrecht: Springer, 2002. p.129-137. 
Tabela 1. Características de interesse para a arte floral e para o mercado consumidor, critérios de avaliação e notas a serem atribuídas a cada uma das características em flores e folhagens de corte nativas e não convencionais (STUMPF, 2007)

Table 1. Traits useful for floral art and market, criteria of evaluation and scores attributed to each trait in non conventional and native cut flowers and foliages (STUMPF, 2007)

\begin{tabular}{lllcl} 
Características e critérios de avaliação & \multicolumn{4}{c}{ Notas } \\
\cline { 2 - 4 } & 0 & 5 & 10
\end{tabular}

Comprimento - Considerado pela medida desde a

base da haste até a parte mais alta das flores, frutos Menor do que 20

ou folhas, ou, no caso de folhas, pelo comprimento $\mathrm{cm}$

Entre 20 e $40 \mathrm{~cm} \quad$ Maior do que $40 \mathrm{~cm}$ do limbo. Medido com régua milimetrada.

\begin{tabular}{|c|c|c|}
\hline $\begin{array}{l}\text { Rigidez da haste ou das folhas - Relacionado com } \\
\text { a necessidade de suporte artificial, como arames e } \\
\text { tutores, para que se mantenham eretos. }\end{array}$ & $\begin{array}{l}\text { Flexível, necessita } \\
\text { reforço para ser } \\
\text { utilizada }\end{array}$ & $\begin{array}{l}\text { Semi-rígida; } \\
\text { necessita reforço de } \\
\text { acordo com o uso }\end{array}$ \\
\hline $\begin{array}{l}\text { Aspecto da haste - Relacionado ao efeito visual } \\
\text { que a haste é capaz de provocar na composição } \\
\text { floral, levando em conta atributos como textura, } \\
\text { espessura e coloração. }\end{array}$ & $\begin{array}{l}\text { Interfere } \\
\text { negativamente na } \\
\text { composição floral, } \\
\text { não deve ficar } \\
\text { exposta ou em } \\
\text { evidência }\end{array}$ & $\begin{array}{l}\text { Não interfere na } \\
\text { composição floral } \\
\text { ou não agrega valor } \\
\text { às composições } \\
\text { florais }\end{array}$ \\
\hline
\end{tabular}

Firme, não

necessita reforço

Interfere

positivamente na composição floral ou agrega valor às composições florais ou contribui positivamente para a estética

Forma da flor ou inflorescência, da folha ou do fruto ou infrutescência - Verificado na estrutura de maior interesse. Relacionado ao efeito visual que provocam na composição floral.

Sem atrativo ou

Comum ou a

valorização

depende da combinação com outros elementos da

Inusitada ou agrega não é a principal característica ornamental composição floral

Rendimento na composição floral - Relacionado ao volume que agregam à composição floral ou pelo número aproveitável de estruturas (número de ramos secundários ou de folhas, por exemplo).

Baixo, contribui
pouco para
aumentar o
volume da
composição floral
Sem atrativo ou
não é a principal
característica
ornamental

Médio, contribui medianamente para aumentar o volume da composição floral valor às composições florais

Comum ou a valorização depende da combinação com outros elementos da composição floral estrutura de maior interesse, com cor identificada em escala de cores CMYK. ornamental

Sem aroma ou Pouco agradável $\begin{aligned} & \text { Sem aroma } \\ & \text { desprezível }\end{aligned}$

Agradável, pode agregar valor às composições florais provocada no avaliador.

Existe semelhante no mercado

Não existe semelhante no mercado

Originalidade - Em comparação
comercializadas, tradicionais.

Considerada pelo tempo, em dias, a partir da coleta a campo até o

Vida útil real descarte, estabelecido pela perda em água das características estéticas de interesse. Equivalente à durabilidade pós-colheita de plantas cultivadas. Avaliada tanto em recipientes com água de Menos de 10 dias Entre 10 e 15 dias Mais de 15 dias

Vida útil real em espuma saneamento urbano como em espuma floral hidratada, mantidos floral em ambiente não controlado. Conservação do nível de água e saturação da espuma floral pela adição de água. 
Tabela 2. Notas atribuídas às características ornamentais de Baccharis articulata, B. usterii, Hypericum connatum, Myrsine umbellata, Schinus lentiscifolius e S. terebinthifolius e grau de potencialidade ornamental de cada uma dessas espécies

Table 2. Scores attributed for the ornamental traits of Baccharis articulata, B. usterii, Hypericum connatum, Myrsine umbellata, Schinus lentiscifolius and $S$. terebinthifolius and their ornamental potential

\begin{tabular}{|c|c|c|c|c|c|c|}
\hline $\begin{array}{l}\text { Características } \\
\text { avaliadas }\end{array}$ & $\begin{array}{l}\text { Baccharis } \\
\text { articulata }\end{array}$ & B. usterii & $\begin{array}{c}\text { Hypericu } \\
m \\
\text { connatum }\end{array}$ & $\begin{array}{l}\text { Myrsine } \\
\text { umbellata }\end{array}$ & $\begin{array}{c}\text { Schinus } \\
\text { lentiscifol } \\
\text { ius }\end{array}$ & $\begin{array}{c}S . \\
\text { terebinthif } \\
\text { olius }\end{array}$ \\
\hline $\begin{array}{l}\text { Comprimento da haste ou } \\
\text { folha }\end{array}$ & 10 & 10 & 10 & 5 & 10 & 10 \\
\hline $\begin{array}{l}\text { Rigidez da haste ou das } \\
\text { folhas }\end{array}$ & 10 & 10 & 10 & 10 & 10 & 10 \\
\hline Aspecto da haste & 10 & 10 & 10 & 5 & 10 & 5 \\
\hline Forma & 10 & 10 & 10 & 10 & 10 & 10 \\
\hline $\begin{array}{l}\text { Rendimento na } \\
\text { composição floral }\end{array}$ & 10 & 5 & 5 & 10 & 10 & 10 \\
\hline Cor e/ou brilho & 10 & 5 & 10 & 10 & 10 & 10 \\
\hline Aroma & 5 & 5 & 5 & 5 & 10 & 10 \\
\hline Originalidade & 10 & 10 & 10 & 10 & 10 & 10 \\
\hline Vida útil real em água & 10 & 10 & 10 & 10 & 10 & 10 \\
\hline $\begin{array}{l}\text { Vida útil real em espuma } \\
\text { floral }\end{array}$ & 10 & 0 & 10 & 10 & 10 & 5 \\
\hline Média das notas obtidas & 95 & 75 & 90 & 85 & 100 & 90 \\
\hline $\begin{array}{l}\text { Grau de potencialidade } \\
\text { ornamental }\end{array}$ & Alta & Alta & Alta & Alta & Alta & Alta \\
\hline
\end{tabular}

